\title{
Clinical Holistic Medicine (Mindful,Short-Term Psychodynamic Psychotherapy Complemented with Bodywork) in the Treatment of Experienced Mental Illness
}

Søren Ventegodt ${ }^{1,2,3,4,5, \star}$, Suzette Thegler ${ }^{2,3,5}$, Tove Andreasen $^{2,3,5}$, Flemming Struve ${ }^{2,3,5}$, Lars Enevoldsen ${ }^{2,3,5}$, Laila Bassaine ${ }^{2,3,5}$, Margrethe Torp ${ }^{2,3,5}$, and Joav Merrick ${ }^{6,7,8,9}$

${ }^{1}$ Quality of Life Research Center, Teglgårdstræde 4-8, DK-1452 Copenhagen K, Denmark; ${ }^{2}$ Research Clinic for Holistic Medicine and ${ }^{3}$ Nordic School of Holistic Medicine, Copenhagen, Denmark; ${ }^{4}$ Scandinavian Foundation for Holistic Medicine, Sandvika, Norway; ${ }^{5}$ Interuniversity College, Graz, Austria; ${ }^{6}$ Zusman Child Development Center, Soroka University Medical Center, Ben Gurion University of the Negev, Beer-Sheva, Israel; ${ }^{7}$ National Institute of Child Health and Human Development and ${ }^{8}$ Office of the Medical Director, Division for Mental Retardation, Ministry of Social Affairs, Jerusalem, Israel

E-mail: ventegodt@livskvalitet.org

Short-term psychodynamic psychotherapy (STPP) complemented with bodywork improved 31 of 54 patients $(57.4 \%, 95 \% \mathrm{Cl}$ : $43.21-70.77 \%)$ who rated themselves mentally ill before treatment. Calculated from this we find $1.41<$ NNT $<2.31$; we estimate NNH > 500. Of the 54 patients, $40 \%$ had already had traditional treatment that did not help them. Bodywork helped the patients to confront repressed painful feelings from childhood and this seemingly accelerated and improved the therapy. The patients received in average 20 sessions over 14 months at a cost of 1600 EURO. For the treatment responders, all measured aspects of life (on a five point Likert Scale) improved significantly, simultaneously, and radically: somatic health (from 2.9 to 2.3), self-esteem/relationship to self (from 3.5 to 2.3), relationship to partner (from 4.7 to 2.9 [no partner was rated as "6"]), relationship to friends (from 2.5 to 2.0), ability to love (from 3.8 to 2.4), selfassessed sexual ability (from 3.5 to 2.4), self-assessed social ability (from 3.2 to 2.1 ), selfassessed working ability (from 3.3 to 2.4), and self-assessed quality of life (from 4.0 to 2.3. Quality of life as measured with QOL5 improved (from 3.6 to 2.3 on a scale from 1 to $5 ; p<0.001)$. This general improvement strongly indicated that the patient had healed existentially, i.e., had experienced what Aaron Antonovsky (1923-1994) called "salutogenesis", defined as the process exactly the opposite of pathogenesis. For the treatment responders, the treatment provided lasting benefits, without the negative side effects of drugs. A lasting, positive effect might also prevent many different types of problems in the future.

KEYWORDS: human development, complementary and alternative medicine, CAM, mental health, Denmark, short-term psychodynamic psychotherapy (STPP), holistic medicine, existential healing, bodywork, salutogenesis, Antonovsky 


\section{INTRODUCTION}

Psychodynamic short-term therapy was proven successful in several meta-studies with mental health problems[1,2,3,4]. The therapy is believed to work even when the patient is suffering from schizophrenia[5]. Since 1997, in our clinical work, we have made psychodynamic therapy more efficient by including bodywork[6] and, in this way, have accelerated the therapeutic process by helping the patient to confront repressed feelings from childhood trauma.

\section{METHODS}

In 2004-2005, we treated 54 patients (15-60 years of age) who rated themselves as mentally ill on a 5point Likert scale of self-assessed mental health when they came to our clinic. We measured the outcome with a validated questionnaire (QOL5)[7] and used the bodywork of Marion Rosen[8]. We included the patients (15-60 years, both genders) that spontaneously appeared in our clinic, which is open towards the street. Of these patients, $40 \%$ had already had traditional psychiatric treatment for a mental disease (mostly depression and schizophrenia) without feeling sufficiently helped. They rated themselves on assessment an average of 3.7 (standard deviation 0.76) on the 5-point Likert scale of self-assessed mental health. The patients received, on average, 20 sessions over 14 months and paid 1,600 EURO.

\section{RESULTS}

We found that almost all patients had spontaneous regression to early childhood trauma when bodywork[8] was used in combination with psychodynamic therapy. Bodywork helped the patient to confront the repressed, often very unpleasant, feelings from childhood trauma(s), which accelerated therapy. Of the 54 patients, 31 (57.4\%, 95\% CI: 43.21-70.77\%) who rated themselves mentally ill before treatment did not do so after treatment (estimated: $1.41<\mathrm{NNT}<2.31)(\mathrm{NNT}=$ Number Needed to Treat); i.e., 54 patients felt mentally ill before treatment (rating 4 or 5 on the 5-point Likert scale of self-assessed mental health of QOL5) and 31 patients did not feel mentally ill after treatment (rating 1, 2, or 3 on the Likert scale). Six patients still felt mentally ill after treatment (rating 4 or 5); 17 were nonresponders on follow-up 1 year after.

Most interestingly, for the treatment responders, all measured aspects of life improved significantly, simultaneously, and radically (see Table 1): somatic health (from 2.9 to 2.3), self-esteem/relationship to self (from 3.5 to 2.3), relationship to partner (from 4.7 to 2.9 [no partner was rated as " 6 "]), relationship to friends (from 2.5 to 2.0), ability to love (from 3.8 to 2.4), self-assessed sexual ability (from 3.5 to 2.4), self-assessed social ability (from 3.2 to 2.1), self-assessed working ability (from 3.3 to 2.4), and selfassessed quality of life (from 4.0 to 2.3) (see Table 1). Quality of life as measured with QOL5 improved (from 3.6 to 2.3 on a scale from 1 to $5 ; p<0.001$ ). This general improvement strongly indicated that the patient had healed existentially, i.e., had experienced what Aaron Antonovsky (1923-1994) called "salutogenesis"[9], defined as the process exactly the opposite of pathogenesis. 
TABLE 1

Patients who Changed from Feeling Mentally III to Mentally Well

\begin{tabular}{|c|c|c|c|c|c|c|c|c|}
\hline & \multicolumn{5}{|c|}{ Paired Differences* } & \multirow{3}{*}{$t$} & \multirow{3}{*}{ df } & \multirow{3}{*}{$\begin{array}{c}\text { Significance } \\
\text { (Two- } \\
\text { Tailed) }\end{array}$} \\
\hline & \multirow{2}{*}{ Mean } & \multirow{2}{*}{$\begin{array}{c}\text { Std. } \\
\text { Deviation }\end{array}$} & \multirow{2}{*}{$\begin{array}{l}\text { Std. Error } \\
\text { Mean }\end{array}$} & \multicolumn{2}{|c|}{$\begin{array}{l}95 \% \mathrm{Cl} \text { of } \\
\text { Difference }\end{array}$} & & & \\
\hline & & & & Lower & Upper & & & \\
\hline Physical health & 0.6000 & 0.89443 & 0.16330 & 0.2660 & 0.9340 & 3.674 & 29 & 0.001 \\
\hline Mental health & 1.9677 & 0.79515 & 0.79515 & 1.6761 & 2.2594 & 13.778 & 30 & 0.000 \\
\hline Self-esteem & 1.2258 & 1.11683 & 1.11683 & 0.8161 & 1.6355 & 6.111 & 30 & 0.000 \\
\hline Relation to friends & 0.5161 & 0.92632 & 0.92632 & 0.1764 & 0.8559 & 3.102 & 30 & 0.004 \\
\hline Relation to partner & 1.8065 & 2.27185 & 2.27185 & 0.9731 & 2.6398 & 4.427 & 30 & 0.000 \\
\hline Ability to love & 1.3548 & 1.60309 & 1.60309 & 0.7668 & 1.9429 & 4.706 & 30 & 0.000 \\
\hline Sexual ability & 1.0323 & 1.35361 & 1.35361 & 0.5358 & 1.5288 & 4.246 & 30 & 0.000 \\
\hline Social ability & 1.1613 & 1.12833 & 1.12833 & 0.7474 & 1.5752 & 5.730 & 30 & 0.000 \\
\hline Work ability & 0.9000 & 1.06188 & 1.06188 & 0.5035 & 1.2965 & 4.642 & 29 & 0.000 \\
\hline Quality of life & 1.7097 & 1.03902 & 1.03902 & 1.3286 & 2.0908 & 9.162 & 30 & 0.000 \\
\hline
\end{tabular}

*Paired samples T-test.

The therapy was found to be safe, as none of more than 500 patients in our clinic over the past years have complained of any serious side effects (standard questionnaires) and, as none was harmed, we estimated the Number Needed to Harm $(\mathrm{NNH})>500$.

The data were collected immediately after treatment and 1 year after. The reported data is from the last measurement we have of the patient. The second follow-ups showed that the mentally ill patients gained from the therapy and also retained the feeling of help 1 year later (for the responders).

\section{DISCUSSION}

An important part of this existential healing happened in a few, very intense days of feeling very bad, when painful and repressed material from old childhood trauma(s) reappeared in the consciousness of the patient. These existential crises were not dangerous, but the patient needed intensive support (sometimes $24 \mathrm{~h}$ /day) during this period. It can be an ethical question whether or not putting patients into this emotional pain is acceptable, but most patients are very grateful when they felt cured afterwards.

We do believe that bodywork, and the recent development in psychodynamic therapy making it more "holistic"[6], has made it more "mindful”, less painful, and much more enjoyable. A strong philosophical focus on the meaning of life of the patient, his/her talents, and positive abilities has contributed to this.

Touching the patient is not allowed in many psychotherapeutic communities and, as the therapeutic touch seems to be the magical key to accelerate healing and Antonovsky-salutogenesis[9], these restricted rules might not be in the best interest of the patient and should therefore be reconsidered. Body therapy is often done with the patient naked or almost naked, and this might be considered as an ethical problem in many countries.

Another problem is that we need to make the study controlled, with randomization to standard treatment, and objective diagnosis. We also need to include more patients in the study and specific groups of mentally ill patients. 


\section{CONCLUSIONS}

The treatment of mental health patients with "clinical holistic medicine" (psychodynamic short-term therapy complemented with bodywork) seems to be extremely efficient in helping the mentally ill patient to improve by inducing existential healing, the so-called Antonovsky salutogenesis[9]. After only 20 sessions of therapy, the quality of life had improved dramatically, the self-esteem had improved, the relation to partner and friends had improved, and even self-assessed somatic health and self-assessed working ability had improved. It has no observed side effects and its results were permanent, judging from a 1-year follow-up.

We estimated the NNT of "clinical holistic medicine" with mentally ill patients to be 1.41-2.31 (1.41 $<$ NNT $<2.31$ ) and the NNH $>500$.

\section{ACKNOWLEDGMENTS}

This study was supported by grants from IMK Almene Fond. The quality of life research was originally approved by the Copenhagen Scientific Ethical Committee under number (KF)V.100.2123/91 and later correspondence.

\section{REFERENCES}

1. Anderson, E.M. and Lambert, M.J. (1995) Short term dynamically oriented psychotherapy: a review and metaanalysis. Clin. Psychol. Rev. 15, 503-514.

2. Leichsenring, F., Rabung, S., and Leibing, E. (2004) The efficacy of short-term psychodynamic psychotherapy in specific psychiatric disorders: a meta-analysis. Arch. Gen. Psychiatry 61(12), 1208-1216.

3. Leichsenring, F. (2005) Are psychodynamic and psychoanalytic therapies effective? A review of empirical data. Int. J. Psychoanal. 86(Pt 3), 841-868.

4. Abbass, A.A., Hancock, J.T., Henderson, J., and Kisely, S. (2006) Short-term psychodynamic psychotherapies for common mental disorders. Cochrane Database Syst. Rev. 18(4), CD004687.

5. Karon, B.P. and VendenBos, G. (1981) Psychotherapy of Schizophrenia. The Treatment of Choice. Jason Aronson, New York.

6. Ventegodt, S., Kandel, I., and Merrick, J. (2005) Principles of Holistic Medicine. Quality of Life and Health. Hippocrates, New York.

7. Ventegodt, S., Kandel, I., and Merrick, J. (2006) Principles of Holistic Medicine. Global Quality of Life. Theory, Research and Methodology. Hippocrates, New York.

8. Rosen, M. and Brenner, S. (2003) Rosen Method Bodywork. Accessing the Unconscious through Touch. North Atlantic Books, Berkeley, CA.

9. Antonovsky, A. (1987) Unravelling the Mystery of Health. How People Manage Stress and Stay Well. Jossey-Bass, San Francisco.

This article should be cited as follows:

Ventegodt, S., Thegler, S., Andreasen, T., Struve, F., Enevoldsen, L., Bassaine, L., Torp, M., and Merrick, J. (2007) Clinical holistic medicine (mindful, short-term psychodynamic psychotherapy complemented with bodywork) in the treatment of experienced mental illness. TheScientificWorldJOURNAL: TSW Holistic Health \& Medicine, 7, 306-309. DOI 10.1100/tsw.2007.67. 


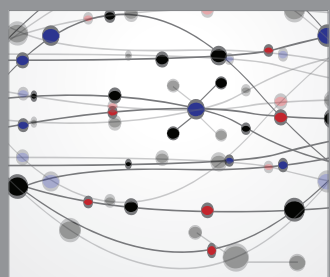

The Scientific World Journal
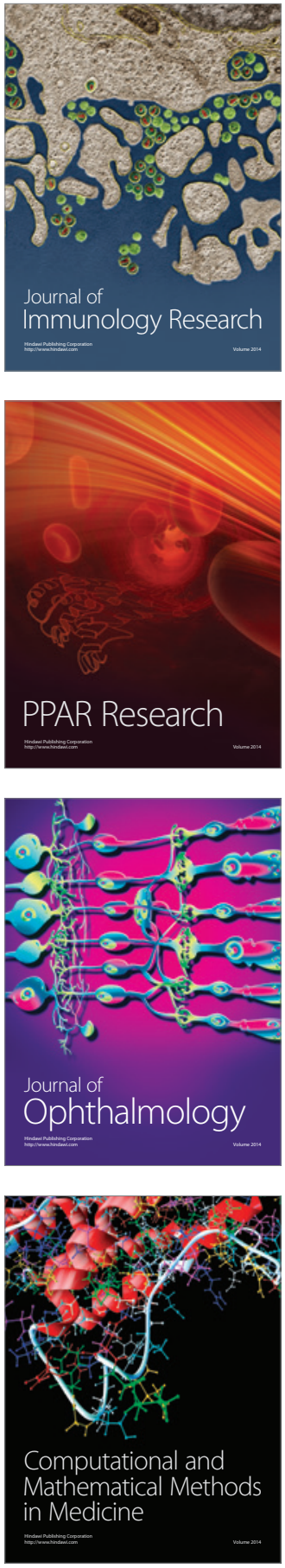

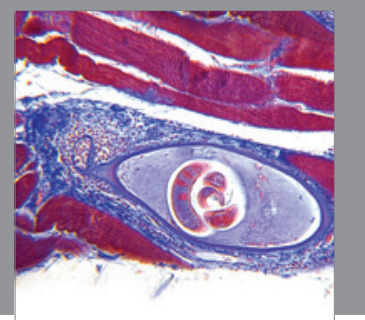

Gastroenterology

Research and Practice
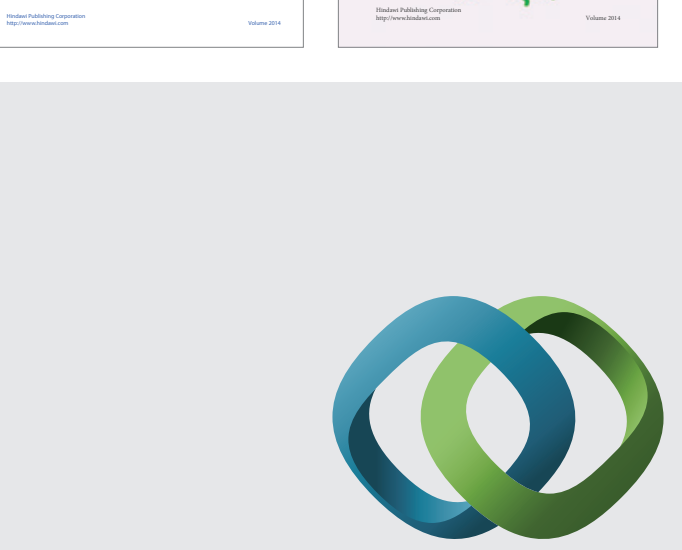

\section{Hindawi}

Submit your manuscripts at

http://www.hindawi.com
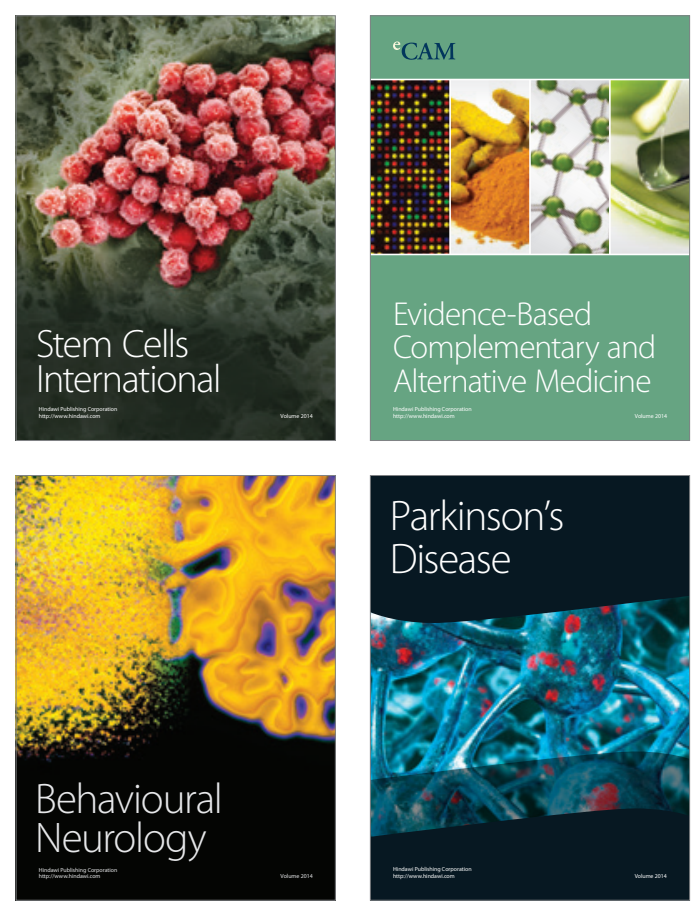

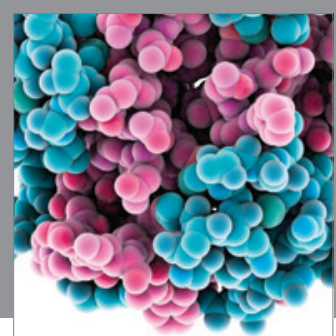

Journal of
Diabetes Research

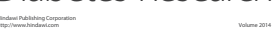

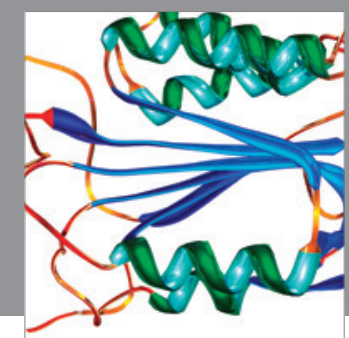

Disease Markers
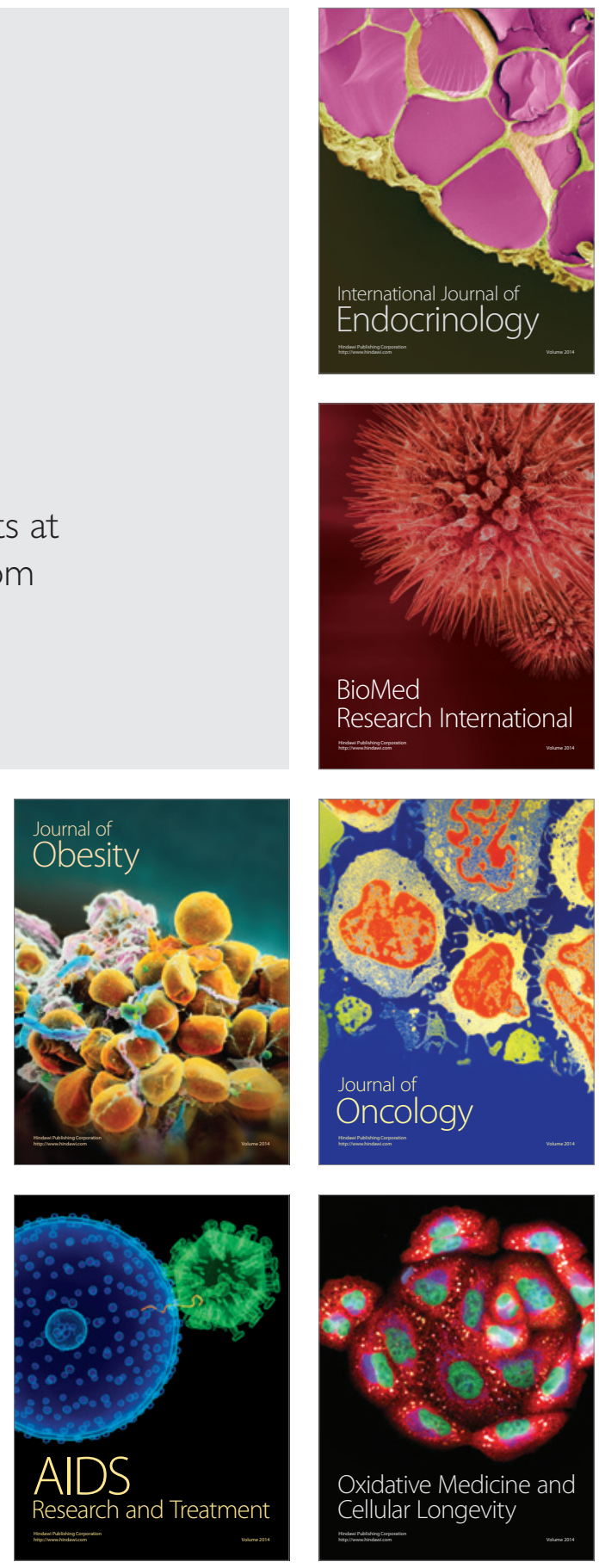